\title{
Structural Configuration Analysis of Advanced Flight Vehicle Concepts with Distributed Hybrid-Electric Propulsion
}

\author{
Vivek Mukhopadhyay, ${ }^{1}$ Thomas A. Ozoroski, ${ }^{2}$ and Mark L. McMillin ${ }^{3}$ \\ NASA Langley Research Center, Hampton, VA 23681
}

\begin{abstract}
Structural configuration analysis of two advanced aircraft concepts with dis tributed hybridelectric propulsion is presented. These concepts are characterized by multiple wing-mounted electric propuls ors, which are powered by turbo-generators. Based on lessons learned from previous structural analysis of unconventional concepts, high-fidelity finite element models of the aircraft wing with embedded electric propulsors are developed. Although a hybrid-electric propulsion system has noise and emis sion benefits, it als o adds electrical power sys tem weights. Hence, efficient structural integration of the wing and propulsors is investigated for design improvement, structural analysis, and weight reduction. Wing structural weights of the two designs are compared with a baseline conventional transport aircraft wing for benefit ass essment. In one design, the wing structural weight reduction partially compensates for the additional weight as sociated with the dis tributed electric propulsion system.
\end{abstract}

\section{Introduction}

Under the NASA Aeronautics Research Mission Directorate (ARMD) Advanced Air Transport Technology (AATT) project, performance, noise and emis sion benefits of distributed turbo-electric propulsion are being investigated. Felder, et al. ${ }^{1}$ reported the impact of boundary layer ingestion on the design of a Turbo-electric Dis tributed Propulsion (TeDP) system integrated into a hybrid wing body (HWB) aircraft. Jensen, et al. ${ }^{2}$ discussed key performance parameters of turbo-electric aircraft. Turbo-electric distributed propulsion benefits on the hybridwing-body type vehicle were presented by Kim, et al. ${ }^{3}$ Wick, et al. ${ }^{4}$ studied the integration challenges and potential benefits of dis tributed propulsion systems on next generation commercial and military transports. Schiltgen, et al. . $^{5}$ described a 150-passenger Environmentally Cons cious tube-and-wing regional airliner concept (ECO-150), which is characterized by a turbo-electric distributed propulsion system embedded within the inboard section of the wing. A novel conceptual design of a single-aisle turbo-electric commercial trans port with fuselage boundary layer ingestion was described by Welstead and Felder. ${ }^{6}$ Gerald $^{7}$ discussed weights and efficiencies of electric components for a turboelectric hybrid-wing-body aircraft propulsion system. A large set of advanced hybrid-electric propulsion concepts was investigated by Bradley, et al. ${ }^{8,9}$ at the Boeing Company. Jensen, et al. ${ }^{10}$ have conducted extensive systems analysis to evaluate the ris ks and benefits of a conversion froman all fuel high by-pass turbofan to a hybrid-electric turbofan engine concept. Jensen also described NASA Electrified Aircraft Propulsion (EAP) research to improve the fuel efficiency, emissions, and noise levels in commercial trans port aircraft. Turbo-electric, partially turbo-electric, and hybrid-electric propulsion systems are the primary EAP configurations being evaluated for regional jet and larger aircraft. The goal is to show that one or more viable EAP concepts exist for narrow-body aircraft.

Although a hybrid-electric propulsion systemhas potential performance benefits, electric generators, motors, and power distribution system add to the overall weight compared to an aircraft with conventional propulsion. The objective of this paper is to investig ate wing structural designs of distributed hybrid-electric propulsion vehicles that would compensate for this additional system weight compared to a conventional aircraft wing. This paper will present structural design and weight analysis of two concepts referred to as Single-Aisle Turbo-electric Aircraft with Leading Edge Embedded Distribution (STARC-LEED) concept-I and STARC-LEED concept-II. The wing-embedded propuls ors in these concepts significantly impact the wing structural design. The weight of this type of unconventional wing structure cannot be determined from historical low-order weight estimation methods. Predicting the weight requires higher order analysis such as the structural finite element analysis. Based on les sons learned fromprevious structural analy sis of unconventional concepts, such as the hybrid-wing-body fuselage section ${ }^{11}$ and large doublebubble fuselage section, ${ }^{12}$ high-fidelity finite element models (FEM) of the aircraft wing with embedded electric fans

\footnotetext{
${ }^{1}$ Aerospace Engineer, Aeronautics Systems Analysis Branch, MS 442, AIAA Associate Fellow.

${ }^{2}$ A rerospace Engineer, Analytical Mechanics Associates, Inc., AIAA Member.

${ }^{3}$ Aeros pace Engineer, Vehicle Analy sis Branch.
} 
have been developed. Wing structure and propulsor integration is investigated to seek an efficient design. Structural sizing and stress analyses of vehicle components are applied for design improvement and weight reduction. The wing FEM weights of the two STARC-LEED concepts are compared with the baseline conventional transport aircraft, to as sess the benefits.

\section{Analysis Approach}

Figure 1 illus trates a range of structural analysis work performed by the author for evaluation of NASA advanced trans port concepts. Much of the past work has focused on unconventional fuselages structures. Figures 1a-ld show finite element models of a hybrid-wing-body vehicle fus elage section, ${ }^{11}$ a conventional cy lindrical section fu selage, a comparable ND8 double-bubble and double-D section fuselage section, ${ }^{12}$ and a double-bubble type vehicle. Note that in evaluating new structural concepts it is important to establish a relevant baseline, such as the cylindrical fuselage shown in Figure 1b. Although fuselage structural concepts are not the focus of the currenteffort, the analysis approach developed in these previous activities has been adopted for the current work. Figure 1e shows the "N+3" technology advanced conventional configuration (N3CC) research vehicle model with high by-pass turbofan engines. This conventional configuration serves as the baseline for ev aluation of the STARC-LEED concepts analyzed in this paper. These vehicles have the same general configuration, except for the wing and propulsion system. Figure if shows an initial STARC-LEED concept with turbo-electric distributed propulsion. This initial concept uncovered several integration challenges for the wing embedded propulsion systemthat were addressed in subsequent iterations of the design. Figures $1 \mathrm{~g}$ and $1 \mathrm{~h}$ show the two final STARC-LEED TeDP concepts, concepts I and II, which are the subject of this paper.

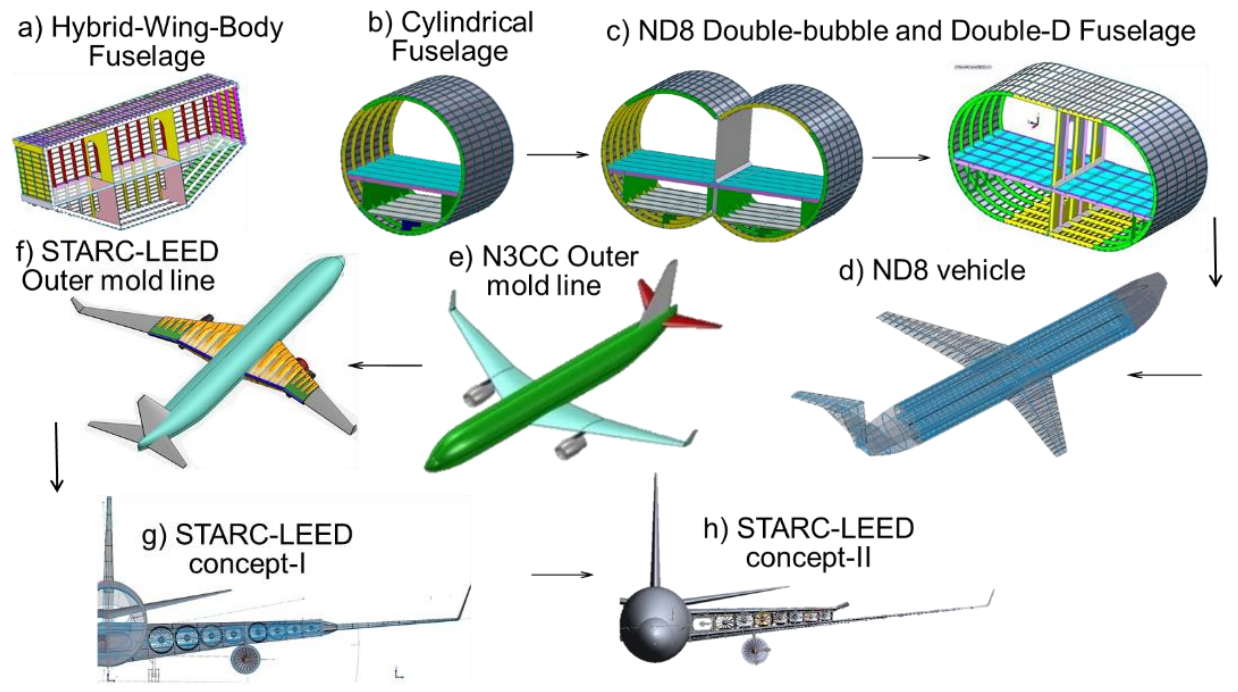

Figure 1. Structural configuration development for advanced air trans port vehicle concepts.

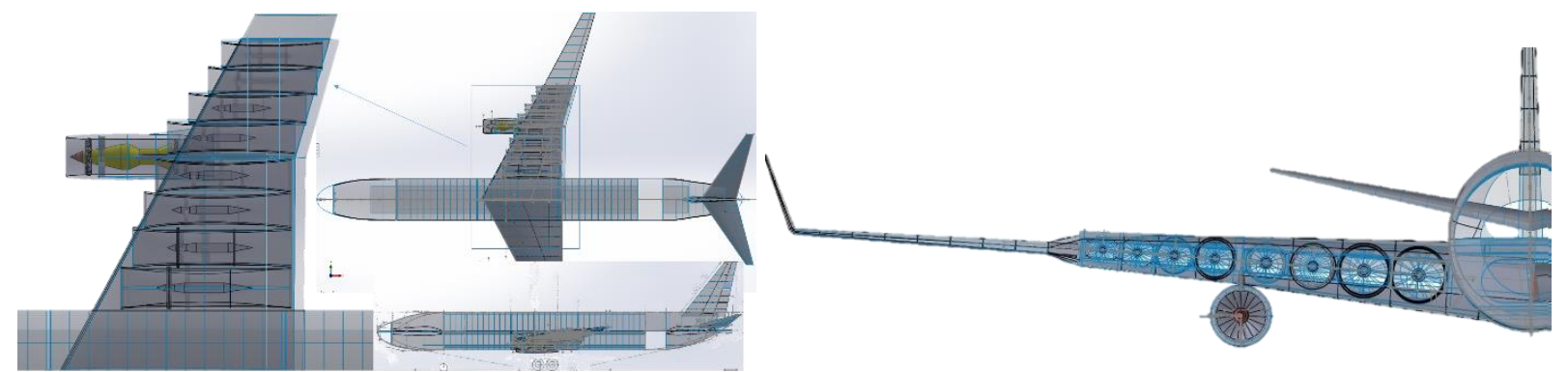

Figure 2.STARC-LEED concept-I with hybrid-electric distributed propulsion integratedinto the wing.

The initial STARC-LEED vehicle outer mold line (OML) was developed using the Open VSP ${ }^{14,15}$ software. However, the wing, fuselage, engineand propulsor models did not have sufficient details, so parasolid models of all internal structure were created using SolidWorks, as shown in Fig. 2. Detailed finite element models of the N3CC and the two final STARC-LEED concepts are analyzed in this paper for structural design and weight prediction using SolidW orks $\mathrm{Sim}^{12}$ simulation s oftware. Figure 2 als o s hows the full vehicle as sembly of the STARC-LEED concept-I 
with sixteen electric fans, which are embedded in the wing. Two underwing turbine engines drive electric generators that power the dis tributed electric propulsors. Figure 3 shows a second dis tributed concept (STARC-LEED conceptII) in which the electric fans are integrated between the main wing and an upper wing, that has a shorter span. Multiple airfoil-shaped chordwise pylons in-between the fans attach the upper wing with the main wing.

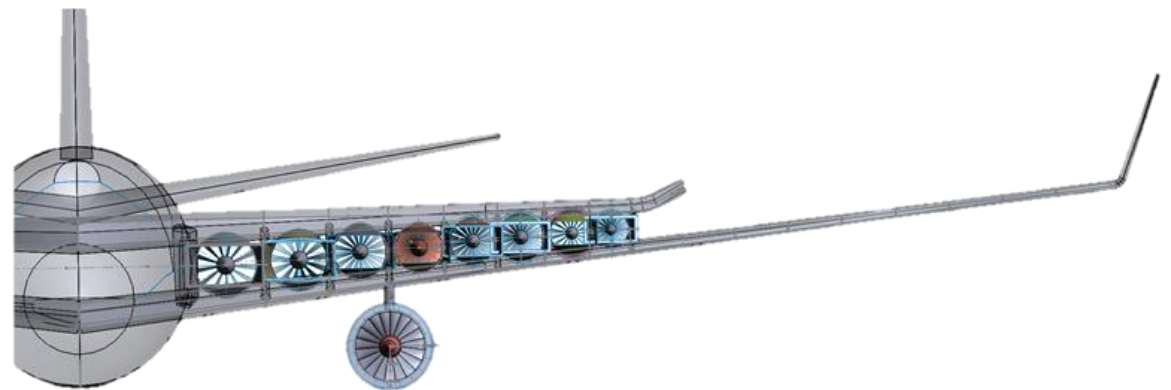

Figure 3.STARC-LEFD concept-II with electric fans integrated between the main wing and an upper wing.

The general structural analysis process starts with development of the detailed geometry, parts, and as sembly within SolidWorks. This is followed by assignment of material properties, component thicknesses, and design loads. After successful meshing and finite element analysis, the stress and dis placement results are plotted and the safety factors are checked. Component skin thicknesses are selected and additional structural elements are inserted or redesigned for better stress dis tribution and dis placement reduction. The design steps are as follows:

1. Develop detailed geometry and finite element model of parts and as sembly.

2. Apply material properties, loads, and boundary conditions.

3. Generate a finite-element mesh and performFEM analys es of parts and assembly.

4. Plot stress, strain, dis placement, and s afety factor dis tributions.

5. Resize and redesign for stress and deformation reduction.

6. Repeat steps 1 through 5 for design feasibility and improvement.

7. Compute structural weight of each component and assembly.

8. Compare the computed weights with existing empirical estimates.

Several analysis cycles are often necessary for both components and the whole as sembly before a reasonable engineering design is obtained that meets design constraints and exhibits weight reduction fromthe previous design.

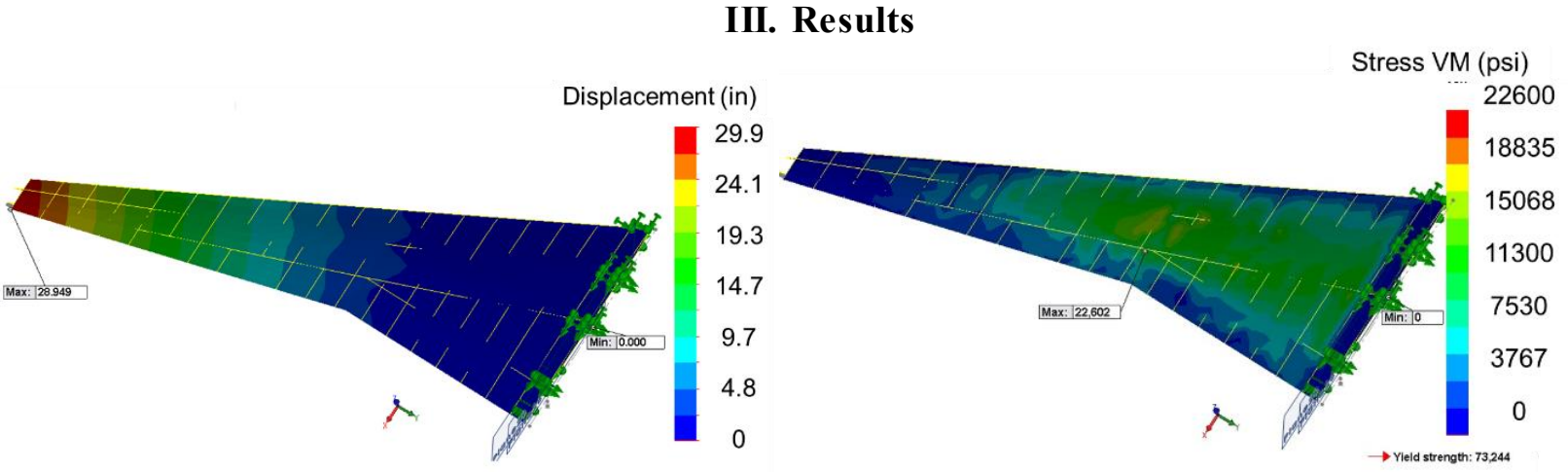

Figure 4. Deflection and stress dis tribution of $\mathrm{N3CC}$ wing with ultimate design load.

The conventional wing of the N3CC configuration (Fig. 1e) serves as the structural baseline for evaluation of the unconventional wing structural concepts. The structural weights of the N3CC and STARC-LEED wings will be compared to determine the structural weight benefits (if any) of the STARC-LEED wing concepts. Figure 4 shows structural deflection and stress dis tributions for the conventional $\mathrm{N} 3 \mathrm{CC}$ wing at the $2.5 \mathrm{~g}$ pull-up lift load with 160,000 $\mathrm{lb}$ takeoff gross weight and a safety margin of 1.5 . This ultimate design load is simulated with a spanwise elliptic pres sure dis tribution on the upper wing surface. The material ass umed is 7075-T6 aluminum alloy. For this analysis, 
all skin, rib, and spar thicknesses are assumed to be $0.2 \mathrm{inch}$. The maximum deflection is 30 inches and the maximum von Mises stress is 22,600 psi. For this conventional N3CC wing, the computed FEM weight is $3979 \mathrm{lb}$ per side.

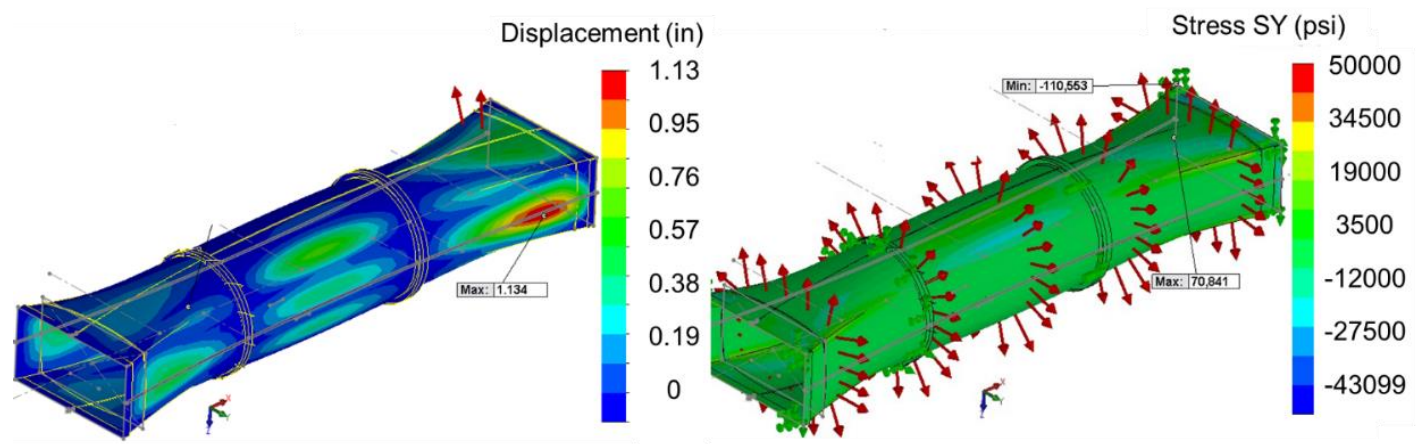

Figure 5. A fan duct dis placement and stress analys is example with 2 psi internal pressure.

A unique aspect of the STARC-LEED wing structure is the internal propulsion ducting. Figure 5 shows deflection and stress distribution from initial finite element analys is of the first inboard fan duct with an internal design pressure of 2 psi and advanced composite material properties. ${ }^{12}$ The dis placement analysis shows 1.13 inch deformation near the rectangular outlets, which required additional reinforcement supports in addition to leng thwise ribs. The circular mid-section of the ducts is reinforced with two blade containment hoops to reduce overall stresses, which are generally below 50,000 psi. However, there are certain high stress areas, which will require local reinforcements. From the FEM analys is, the total fan duct weight of the four inboard ducts is es timated to be $505 \mathrm{lb}$. For the four outboard fan ducts, total weight is estimated to be $255 \mathrm{lb}$. Duct weights includes the outer shell, reinforcements at the rectangular inlets and outlets, blade containment hoops, and chord-wise ribs. The total $760 \mathrm{lb}$ weight of eight ducts do not include the internal rotary components or motors. The entire hybrid-electric propulsion system concept along with detailed geometry of each propulsor was developed and evaluated at NASA Glenn. The total weight of the propulsion system was es timated with the NPSS/WATE++ code. ${ }^{16}$

Figures 6 and 7 show the STARC-LEED concept-I wing model internal structure development, assembly, and initial analys is results. In this initial configuration, four fans are placed inside the wing, inboard of the turbo-generator, and four fans are placed outboard. Figure 6 also shows the internal spar and rib structure. The inboard ribs are placed between the propulsors. In the finite element model, the upper and lower skin s at the inboard section cover the entire propuls ors to formchordwise and spanwise streamlined wing surfaces.
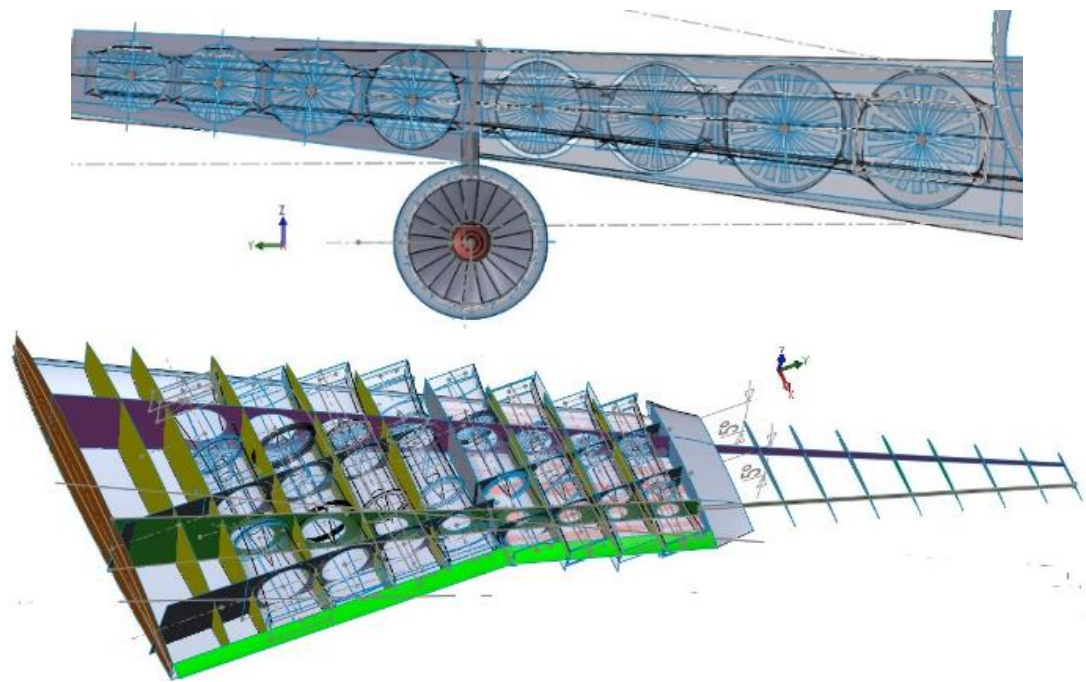

Figure 6.STARC-LEFD concept-I wing and fan duct internal structure development. 

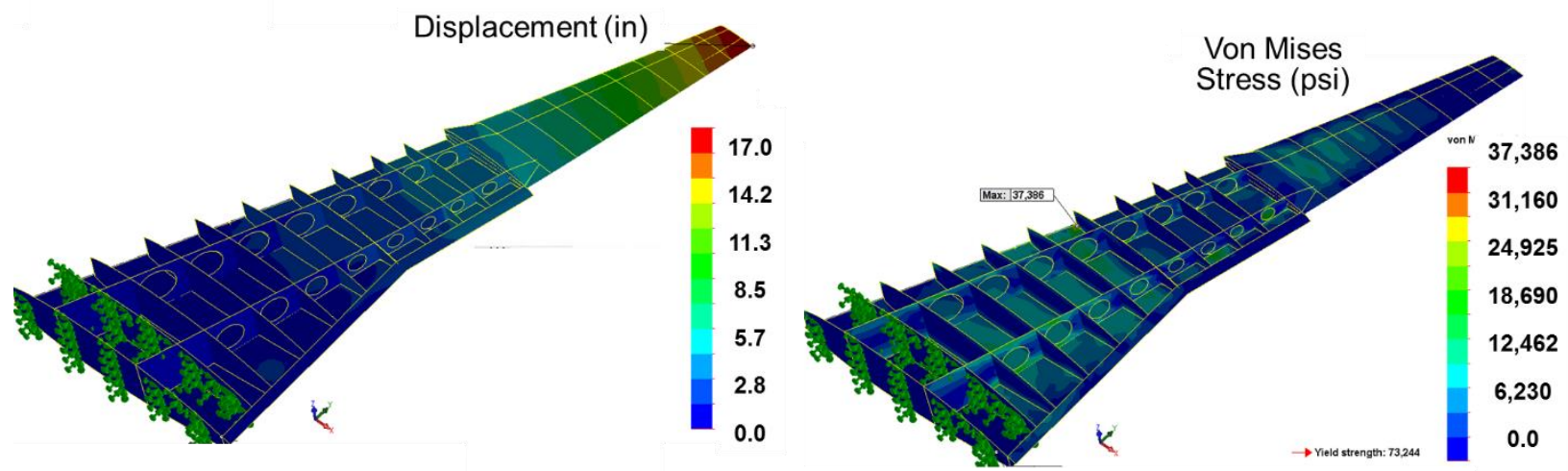

Figure 7. Deflection and stress dis tribution of STARC-LEED concept-I wing with ultimate design load.

The STARC-LEED concept-I wing has higher bending stiffness at the in board section than that of the N3CC wing. The higherbending stiffness of the wing is due to the higher rib and spar heights. The upper and lowers sins on the inboard wing are farther apart to enclose the embedded fan ducts. This wing and airfoil cross-section geometry increases the bending stiffness. Therefore, a smaller skin thickness of 0.05 inch can be used. The wing has a rib thicknes s of $0.1 \mathrm{inch}$, and spar thickness of $0.2 \mathrm{inch}$. At the mid-wing transition fairing area, skin thickness is $0.1 \mathrm{inch}$. Figure 7 shows the wing deflection and von Mis es stress distributions at the $2.5 \mathrm{~g}$ ultimate design load condition. This wing has lower deflection than that of the N3CC wing (Fig. 4) for the same wing load. The maximum von Mises stres ses are higher, but within the allowable limits. In Fig. 7, the upper cover of the inboard section of the wing is removed to show the internal rib and spar arrangementfor accommodating the fan ducts. The inboard front and rear spars have large cutouts for this purpose. Large stresses occur near these cutouts and will require local reinforcements. The STARC-LEED concept-I wing has a maximum deflection of 17 inches at the wing tip. The maximum von Mises stress is $\sim 37,000 \mathrm{ps} i$ at the mid-wing transition area and spar cutouts, but this value is well within the allowable limits of the 7075-T6 aluminum alloy material ( 73,000 psi).
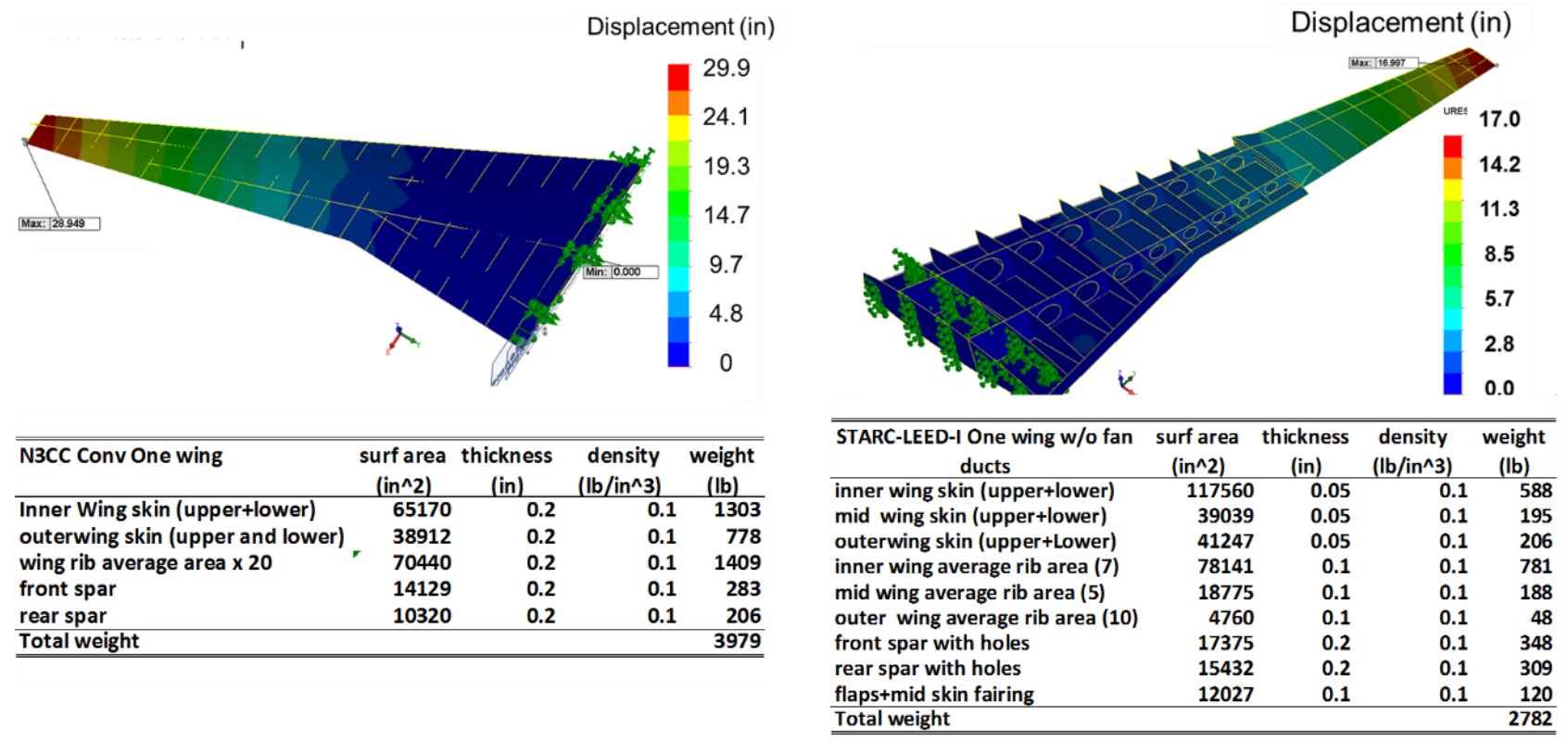

Figure 8. Comparis on of the N3CC and STARC-LEED-I wing deflections and FEM weights (one side).

Figure 8 shows a comparis on of the deflections for the baseline N3CC wing (from Fig 4) and the STARC-LEED concept-I wing (fromFig. 7) and the corresponding FEM weight es timates of one (right or left) side wing. The FEM weight of the N3CC conventional wing is estimated to be $3979 \mathrm{lb}$ (one side). The wing FEM weight of the STARCLEED concept-I is $2782 \mathrm{lb}$ per side, which is $1197 \mathrm{lb}$ (or 30\%) less than that of the N3CC wing. But this $\sim 2400 \mathrm{lb}$ 
weight saving (for two wings) is only a fraction of the additional propulsion system weight as sociated with the distributed electric propulsion system. The weight of 8 ducts will add $760 \mathrm{lb}$ per side. Although the STARC-LEED concept-I wing design results in a structural weight savings compared to the N3CC wing, this only partially offsets the additional weight as sociated with the dis tributed electric propulsion system. The 16 electric motors alone add an additional propulsion system weight of almos $4000 \mathrm{lb}$ to STARC-LEED. Therefore, the STARC-LEED concept as a whole has a weight disadvantage compared to the $\mathrm{N} 3 \mathrm{CC}$. The aerodynamic drag differences will also affect overall performance.

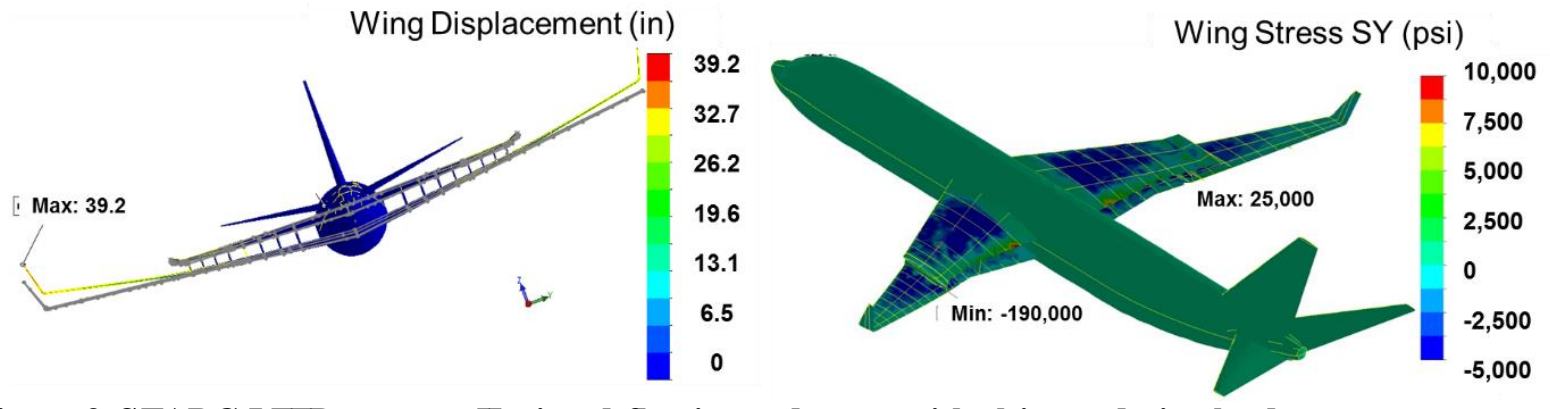

Figure 9.STARC-LEFD concept-II wing deflection and stress with ultimate design load.

Integration of the propulsors into the concept-I wing led to a number of compromises in the wing planform and airfoil geometry. Concept-II was developed as an alternative approach to avoid some of the geometric integration challenges faced with concept-I. This arrangement facilitates better access to the electric-propulsors for maintenance, and perhaps results in cleaner aerodynamic flow. Figure 9 shows the wing dis placement and stress analysis results for the alternative STARC-LEED Concept-II (Fig. 3). In the initial analys is with 7075-T6 alu minum alloy, us ing all skin and rib thicknesses of 0.1 inch and all spar thicknesses of $0.5 \mathrm{inch}$, the wing tip deflection is $39.2 \mathrm{inch}$ at the $2.5 \mathrm{~g}$ ultimate design load. There are still some design and modeling is sues at the wing-pylon junctions, which exhibit large local stres ses. But, in general, the tensile and compressive s tresses on the wing skin in the spanwise direction are fairly low, indicating this mightbe an over-design. Based on this single ad-hoc design, the right upper and lower wing weight are $2193 \mathrm{lb}$ and $2666 \mathrm{lb}$, respectively. The total weight of nine pylons between the eight propuls ors is $1061 \mathrm{lb}$. Total wing weight is $5920 \mathrm{lb}$. The deflection are higher than those for the N3CC conventional wing (Fig. 4) and the STARCLEED concept-I wing (Fig. 7). Although, this configuration is very innovative, additional high fidelity structural design optimization of the wing is necessary to reduce the structural weight.

\section{Conclusions}

The emission, noise, propulsion, and aerodynamic performance enhancements associated with distributed hybridelectric propulsion come at the cost of additional weight from the electric power dis tribution system, generators, and electric propuls ors. It has been postulated that the greater structural depth associated with a wing embedded propulsion approach would provide a structural weight advantage over conventional configurations. Detailed finite element models of two such concepts have been developed and analyzed. The structural integration of the electric propulsors embedded inside the wing or between a partial bi-wing are key factors in these wing designs. A number of design scenarios have been examined through a knowledge-based iterative analysis process to arrive at a wing structural configuration and weight estimation. The initial finite element model analys is of one hybrid-electric propulsion wing concept shows a potential reduction in the structural weight when compared to that of the conventional wing. This reduction, however, will only partially compensate for the additional weight associated with the distributed electric propulsion system. A second concept was developed to address some of the propulsion integration challenges encountered with the first. Initial structural analysis of this design indicates that the wing structural weight is actually higher than that of the baseline conventional wing. This particular concept, therefore, does not appear to offer any structural weight advantage to offset the higher propulsion system weight. The result of this work shows this distributed hybrid-electric propuls ion concept has a net weight disadvantage that will have to be offset by aerodynamic and propulsion efficiency advantages in order for the concept to have a system level fuel consumption benefit. Although these initial weight results are not favorable, additional follow-up structural and aerodynamic analy ses are neces sary for the two hybrid-electric propulsion concepts in order to assess their overall systemlevel performance. 


\section{Acknowledgments}

The authors thank the Advanced Air Transport Technology (AATT) Project for funding this research. We thank AATT Project Manager, JimHeidmann, and AATT Systems Analysis \& Integration Leads, WilliamHaller and Mark Guynn, Daniel Williams, Former Acting Associate Director and William Kimmel, Chief Technolog ist, Sys tems Analy sis and Concepts Directorate for supporting this effort. Authors acknowled ge significant encouragement and innovative ideas from Philip Arcara, Acting Branch Head, and Mark Guynn, Acting Assistant Branch Head, Aeronautics Systems Analysis Branch, Systems Analy sis and Concepts Directorate. Thanks are also due to all the technical reviewers for improving the paper significantly. Technical discussion with Mark Guynn, Mike Tong, Jim Felder, Dr. Jason Welstead, Dr. Wu Li, Dr. Erik Olson, Dr. Jesse Quinlan, Dr. Frank Gern, and Andrew Hahn are greatly appreciated.

\section{References}

${ }^{1}$ Felder, J., Kim, H., Brown, G., and Chu, J., “An Examination of the Effect of Boundary Layer Ingestion on Turboelectric Distributed Propulsion Systems”, AIAA Paper 2011-300,2011.

2 Jansen, R. H., Brown, G. V., Felder, J. L. and Duffy, K. P., “Turboelectric Aircraft Drive Key Performance Parameters and Functional Requirements,” AIAA Propulsion and Energy Forum, Orlando, AIAA Paper 2015-3890, 2015.

${ }^{3}$ Kim, H., Felder, J., Tong, M., Berton, J., and Haller, W., "T urboelectric Distributed Propulsion Benefits on the N3-X Vehicle", Aircraft Engineering and Aerospace Technology: An International Journal, Vol. 86, Issue 6, pp. 558-561, 2014.

4 Wick, A. T., Hooker, R. J., Hardin, C. J., and Zeune, C. H., "Integrated Aerodynamic Benefits of Distributed Propulsion," Lockheed Martin, AIAA Sci. Tech, 53rd AIAA Aerospace Sciences Meeting, AIAA Paper 2015-1500, January 2015.

${ }^{5}$ Schiltgen, B. T., Freeman, J. L., and Hall, D. W., “Aero propulsive Interaction and Thermal System Integration within the ECO150: A T urboelectric Distributed Propulsion Airliner with Conventional Electric Machines," AIAA Aviation Forum 2016, AIAA Paper 2016-3589, June 2016.

${ }^{6}$ Welstead, J. and Felder, J. F., “Conceptual Design of a Single-Aisle Turboelectric Commercial Transport with Fuselage Boundary Layer Ingestion", 54 ${ }^{\text {th }}$ AIAA Aero-sciences Meeting, San Diego, AIAA Paper 2016-1027, January 2016.

${ }^{7}$ Gerald, V., "Weights and Efficiencies of Electric Components of a Turboelectric Aircraft Propulsion System", AIAA Paper 2011225, 2011.

${ }^{8}$ Bradley, M. K. and Droney, C. K., “Subsonic Ultra Green Aircraft Research: Phase I Final Report." NASA/CR-2011-216847, 2011, Boeing Company.

9 Bradley, M. K. and Droney, C. K., "Subsonic Ultra Green Aircraft Research: Phase II - Volume II - Hybrid Electric DesignExploration," NASA/CR-2015-218704/Volume II, 2015, Boeing Company.

10 Jansen, R. H., Bowman, C., Jankovsky, A., Dyson, R. and Felder, J.: NASA Glenn Research Center, Cleveland, Ohio, 44135, "Overview of NASA Electrified Aircraft Propulsion Research for Large Subsonic Transports," NASA/NTRS document 20170006235 , Washington, DC, 2017.

${ }^{11}$ Mukhopadhyay, V., "Composite Structure Modeling and Analysis of Advanced Aircraft Fuselage Concepts”, AIAA Modeling and Simulation Technology Conference, Dallas, AIAA Paper 2015-3096, June 2015.

12 Mukhopadhyay, V., Welstead, J., Quinlan, J. and Guynn, M., "Structural Configuration Systems Analysis for Advanced Aircraft Fuselage Concepts," AIAA Modeling and Simulation Technology Conference, AIAA Paper 2016-4419,2016.

13 SolidWorks and SolidWorksSim User Manual, SolidWorks Corporation, Dassault Systèmes, Concord, Massachusetts.

14 Gloudemans, J. R., McDonald, R., "Improved Geometry Modeling for High Fidelity Parametric Design," 48th AIAA Aerospace Sciences Meeting and Exhibit, AIAA Paper 2010-659, 2010.

15 Hahn, A., "Vehicle Sketch Pad: Parametric Geometry for Conceptual Aircraft Design," 48th AIAA Aerospace Sciences Meeting Orlando, AIAA Paper 2010-657, January, 2010.

16 Tong M. T., "Weight Analysis of T urbine Engines - an Object Oriented Version (WATE++ LEW -19687-1)" New Technology Report, NASA Glenn Research Center, August 2017. 